smokers. The rate of taking caffeinated beverages was $90.4 \%$, of which $75.5 \%$ were taking six or more cups a day. In the form of working for 14-15 hours a day alone and working in fixed night shift, more than 6 cups were consumed.

Taxi drivers are forced to work long hours on their own due to their low wage structure, and the frequency of smoking and caffeine ingestion is very high in order to maintain long working hours. In order to improve this situation, the introduction of the monthly salary system and regulation of working time should be applied.

\section{P.1.18 FACTORS RELATED TO LOWER URINARY TRACT SYMPTOMS OF FEMALE WORKERS IN THE ELECTRONIC PARTS INDUSTRY IN KHON KAEN PROVINCE}

\begin{abstract}
${ }^{1}$ Phanumas Krisorn*, ${ }^{1}$ Naesinee Chaiear, ${ }^{2}$ Pattranit Songsrichainun, ${ }^{2}$ Suchanaree Laitrakul, ${ }^{2}$ Wipawee Keerativorasakul, ${ }^{2}$ Ratchanon Jiraudomrat, ${ }^{2}$ Jirath Intarachai, ${ }^{2}$ Thitipong Saelim. ${ }^{1}$ Division of Occupational Medicine, Department of Community Medicine, Faculty of Medicine, Khon Kaen University, Khon Kaen, Thailand; ${ }^{2}$ Fifth year medical students, Faculty of Medicine, Khon Kaen University, Khon Kaen, Thailand
\end{abstract}

\subsection{6/OEM-2019-EPI.221}

Background The lower urinary tract symptoms (LUTS) are more common in women than men. The causes of LUTS come from many factors. Working factor might be one of them. Leading to a study of working factors and non-working factors related to LUTS at electronic parts factory in Khon Kaen province.

Methods The case-control study was performed. The total of 236 cases (female worker who has at least one symptom of LUTS) and 236 controls (female workers who don't have the symptoms) was done by simple random sampling. Research tool is the self-administered questionnaire. Data were analyzed by SPSS Version 19, EpiInfo for calculate odds ratio, 95\% CI , Pearson's chi-square test and Mann-Whitney U test.

Results Conveyor does not statistically significant related to LUTS $(A O R=0.88,95 \% \mathrm{Cl}(0.59,1.30)$. Factors that significantly related to LUTS are 1 .History of LUTS in a last year $[\mathrm{AOR}=4.80,95 \% \mathrm{CI}(2.64,8.73)] 2$. inadequate number of drinking water glasses $[\mathrm{AOR}=2.15,95 \% \mathrm{CI}(1.06,4.36)] 3$. inadequate number of toilet $[\mathrm{AOR}=1.97,95 \% \mathrm{CI}(1.24,1.97)]$ 4. Holding bladder $[\mathrm{AOR}=1.56,95 \% \mathrm{CI}(1.24,1.97)]$.

Conclusion Conveyor is not a statistically significant factor for LUTS. Statistically significant factors related to LUTS are history of LUTS in a last year, insufficient number of glasses, insufficient number of toilet and holding bladder.

\section{P.1.19 INCREASED BENEFIT GENEROSITY AND THE IMPACT ON WORKERS' COMPENSATION CLAIMING BEHAVIOUR: AN INTERRUPTED TIME SERIES STUDY IN VICTORIA, AUSTRALIA}

Tyler Lane*, Shannon Gray, Luke Sheehan, Alex Collie. Monash University, Melbourne, Australia

\subsection{6/OEM-2019-EPI.222}

Objective To measure the effect of legislated increases to workers' compensation benefits on claiming behaviour.

Methods Interrupted time series of workers' compensation claims in Victoria, Australia (2008-2012), assessing 1) the overall effect of the legislation and 2) raising the wage replacement cap on higher earners, by condition type, in reference to a comparator of other Australian workers' compensation jurisdictions.

Results Overall claiming increased $11.7 \%$, driven largely by musculoskeletal condition claims. There was no detectable effect on disability duration overall, though back/neck conditions were up 26.9\%. Among higher earners, there was mixed evidence of an increase in claiming, though disability durations were up $32.9 \%$, which was also driven by back/neck conditions. There was mixed evidence of an effect on mental health claims, suggesting either no response or a negative response to benefit generosity.

Conclusions Findings mainly align with existing evidence: more generous benefits increase claiming and disability durations, primarily driven by back/neck musculoskeletal conditions. However, some mixed findings by injury group and among higher earners raise questions about confounders such as co-occurring events.

\section{P.1.20 TRENDS IN PREVALENCE OF OBESITY ACCORDING TO OCCUPATIONAL GROUP : THE KOREAN NATIONAL HEALTH AND NUTRITION EXAMINATION SURVEY}

Jea-Yong Lee*, Mo-Yeol Kang, Hyoung-Ryoul Kim, Jun-Pyo Myoung. Department of Occupational and Environmental Medicine, College of Medicine, The Catholic University of Korea., Seoul, South Korea

\subsection{6/OEM-2019-EPI.223}

Objectives This study was designed to provide recent trends of obesity among workers in Korea, and identify whether there was difference across occupational group.

Methods We used data from Korean National Health and Nutrition Examination survey phase I to VI (1998-2015) to analyze trends in prevalence of obesity in Korean adult workers. Obesity was defined as a BMI of $25 \mathrm{~kg} / \mathrm{m} 2$ or higher. Occupation was classified into 3 groups; a) non-manual worker, b) service/sales worker, c) manual worker.

Result During the period from KNHANES phase I to VI, the prevalence of obesity in male workers increased in all occupations as a whole $(31.1 \%$ to $39.5 \%$ in manual worker, $32.3 \%$ to $38.2 \%$ in service/sales worker, $25.3 \%$ to $39.7 \%$ in manual worker). In contrast, female workers did not show a particular tendency except for a significantly decreasing in the prevalence rate in service/sales workers $(30.8 \%$ to $23.9 \%$, p for trend 0.0048).

Conclusions The trends of obesity prevalence by gender and occupation were different. Especially for male manual-workers, the prevalence rate has increased steadily during the period, while it has decreased steadily in female sales/service workers. These results can be used to select vulnerable groups that can be applied to obesity prevention programs first.

\section{P.1.21 THE ESTABLISHMENT OF A COHORT STUDY IN A SEMICONDUCTOR COMPANY OF SOUTH KOREA}

Jiae Lee*, Gyeongho Lee, Woojin Jung, Enjung Kim, Gawon Kim, Wonwoong Na, Saeyoung Lee. SKHynix Semiconductor Inc., Icheon, South Korea

\subsection{6/OEM-2019-EPI.224}

We have designed a ten-year prospective cohort study in semiconductor workers of South Korea. We aimed to determine the relationship between occupational exposure 